\title{
Grain Boundary Sliding in Surface Mount Solders During Thermal Cycling
}

\author{
Seong-Min Lee and Donald S. Stone \\ Department of Materials Science and Engineering \\ University of Wisconsin, Madison
}

\begin{abstract}
This article reports the growth of fatigue cracks in near-eutectic, surface mount solder joints during cyclic, thermal displacement-controlled loading. Ceramic leadless chip carriers (LLCC) are subjected to thermal fatigue with a frequency of $1 / \mathrm{hr}$ and over two ranges of temperature: $-36^{\circ} \mathrm{C}$ to $125^{\circ} \mathrm{C}$ and $-20^{\circ} \mathrm{C}$ to $75^{\circ} \mathrm{C}$. Surfaces and cross-sections of the solder joints are inspected using scanning electron microscopy. Individual grains (colonies of lamellae and globulae) are found to slide relative to one another during thermal cycling. Sliding causes fatigue cracks to initiate at the surface.
\end{abstract}

\section{Introduction}

Intergranular failure is observed in the fatigue of $\mathrm{Pb}$ [1], $\mathrm{Pb}$-rich solders [2-4], $\mathrm{Pb}$-Sn eutectic solders [5,6], and other engineering alloys [7] under service at elevated homologous temperatures. Often contributing to intergranular failure, grain boundary sliding has been recognized as responsible for the nucleation and growth of $w$ - and $r$-type cavities at elevated temperatures [8].

Raman and Reiley [2] have demonstrated how grain boundary sliding leads to initiation and growth of fatigue cracks at the surfaces of solid solution $\mathrm{Pb}-\mathrm{Sn}$ alloys. They observe both the sliding and migration of grain boundaries. Fatigue cracks initiate at boundaries that slide but do not migrate. Boundaries that both migrate and slide show no appreciable cracking.

It is reasonable to suppose that sliding between grains near the specimen surface causes grain boundaries to become exposed to the atmosphere [9]. The boundaries become contaminated with an oxide and are unable to weld back together upon reverse straining. A model of the effects of grain boundary sliding and a contaminating atmosphere on fatigue life has been presented elsewhere [9]. It rationalizes observations by Vaynman et al. [3] on the strain range and frequency dependencies of fatigue life in Pb-rich alloys. The model rationalizes a reduced life in air compared to vacuum and a stronger tendency for failure to be intergranular in air than vacuum $[1,10]$. It also explains why pure lead can fail intergranularly at much higher frequencies of cycling than alloys in which grain boundary sliding is impeded (compare observations of Vaynman et al. [3] with those of Snowden [1]).

Stone et al. [11] proposed grain boundary sliding as a deformation mechanism and potential reliability concern in eutectic solder joints under cycling at low frequencies. Precisely what constitutes a "grain" with respect to either sliding or fatigue in the eutectic alloy was not identified. Specifically, there are several interfaces in the eutectic that might qualify as "grain" boun. daries relevant to sliding and fatigue.

The $\mathrm{Pb}$-Sn eutectic contains, of course, two phases, and the initial microstructure will range from lamellar to globular, depending on rate of solidification [12]. In the lamellar eutectic, boundaries between individual plates of $\mathrm{Pb}$ and $\mathrm{Sn}$ allow sliding as discussed by Cagnon et al [13]. Cracking can occur at phase boundaries as reported by Smeby [14].

It is also possible that individual colonies of lamellae can slide with respect to one-another. As indirect evidence of this sliding, Raman and Reiley [6] have reported the presence of cavities and cracks along boundaries between colonies under fatigue loading. They proposed stress concentrations introduced during sliding between colonies cause the cracking, but noted a lack of supporting evidence in the literature to demonstrate that sliding between colonies occurs.

In view of the observations by Raman and Reiley and the role of grain boundary sliding in the fatigue of a number of other alloys, we decided to determine whether boundaries between colonies of lamellae in the eutectic solder slide. We also wished to determine whether sliding contributes to failure. To maintain relevance, we chose to focus on actual solder joints and to introduce the mechanical loading through a mismatch in thermal expansion. This article reports some results of this research; preliminary results have been reported elsewhere [15].

\section{Experimental Procedure}

Ceramic leadless chip carriers (LLCC) soldered to printed circuit boards were utilized. The specimens were provided by Jim Wooldridge of Rockwell International. Solders in these specimens were intermediate between lamellar and globular, with both microstructures being evident in any particular solder joint. There were relatively few dendrites characteristic of the off-eutectic composition. Occasional acicular precipitates were found, indicating presence of intermetallic compounds.

Specimens were cycled in a Tenney-5 thermal cycle chamber under two (nominal) ranges of temperature: $-35^{\circ} \mathrm{C}$ to $+125^{\circ} \mathrm{C}$ and $-20^{\circ} \mathrm{C}$ to $+75^{\circ} \mathrm{C}$. A thermocouple placed near the specimen was used to monitor air temperature. The frequency of the thermal cycle was $1 / \mathrm{hr}$ as shown in figure 1 . LLCC samples were cycled between 0 and 400 times prior to removal for inspection.

Surfaces and cross-sections of solder joints were viewed under a scanning electron microscope (SEM). Sectioning was performed by grinding with successive grit-sizes down to 600 , then polishing with 6 and $1 \mu \mathrm{m}$ ria 'rond. 


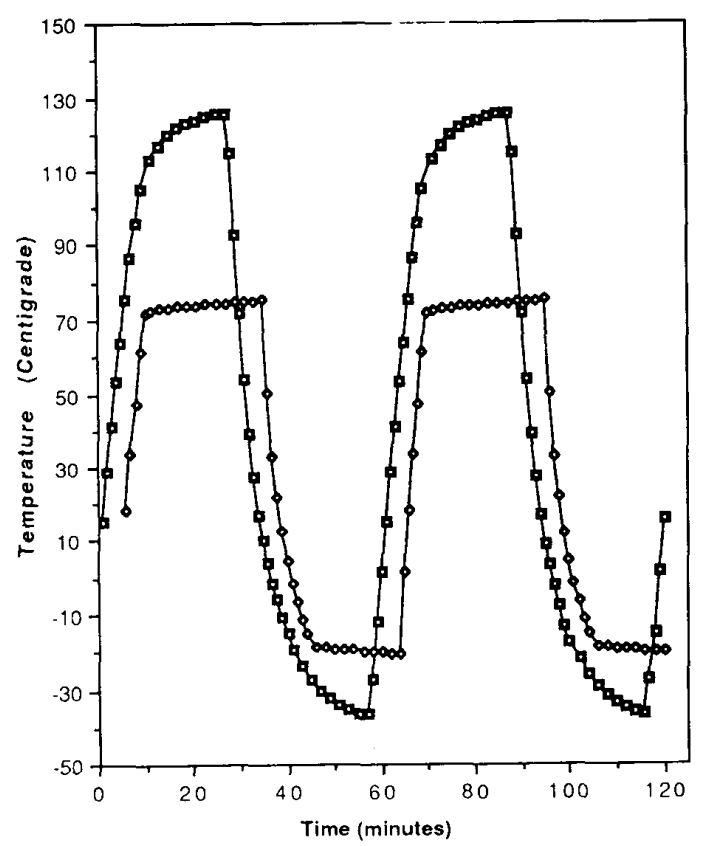

Figure 1. Temperature vs time profiles for the thermal cycle tests performed in this work.

\section{Results}

Figure 2a is a secondary electron image (SEI) of a solder joint prior to thermal cycling. Note the smooth surface. Individual colonies of the eutectic are observed at higher magnification and in the backscattered imaging mode (BEI), figure $2 \mathrm{~b}$.

Cycling a specimen 200 times between $-35^{\circ} \mathrm{C}$ and $125^{\circ} \mathrm{C}$ was sufficient to propagate cracks entirely through a large fraction $(\approx 20 \%)$ of the solder joints. Similar damage was obtained in samples cycled 400 times between $-20^{\circ} \mathrm{C}$ and $75^{\circ} \mathrm{C}$. Figure 3 is the SEI micrograph of a cross-sectioned solder joint where cracks have not passed entirely through the solder. We observed initiation of cracks at at least two locations: the outside surface of the fillet (A) and beneath the carrier (B).

Due to a thin $(10-20 \mu \mathrm{m})$ layer of solder separating carrier and printed circuit board, strains in the solder beneath the carrier were very high. The rate of propagation of the crack initiating at point $B$ (B-crack) was correspondingly high until it reached the fillet. For instance, within 10 cycles between $-35^{\circ} \mathrm{C}$ and $125^{\circ} \mathrm{C}$, some cracks were found to have propagated entirely out from beneath the LLCC.

After the B-crack entered the fillet, the rate at which it propagated reduced considerably. For instance, figure 3 shows a typical B-crack after 50 cycles; it has not propagated to the surface of the fillet. The tip regions of B-cracks after 50 cycles are shown in figure 4. These cracks have a tendency to travel near boundaries between phases, consistent with observations of

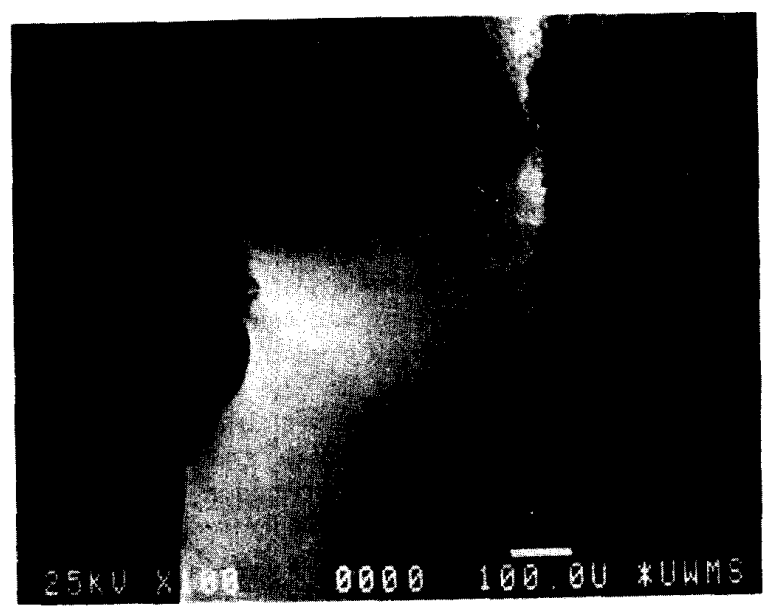

(a)

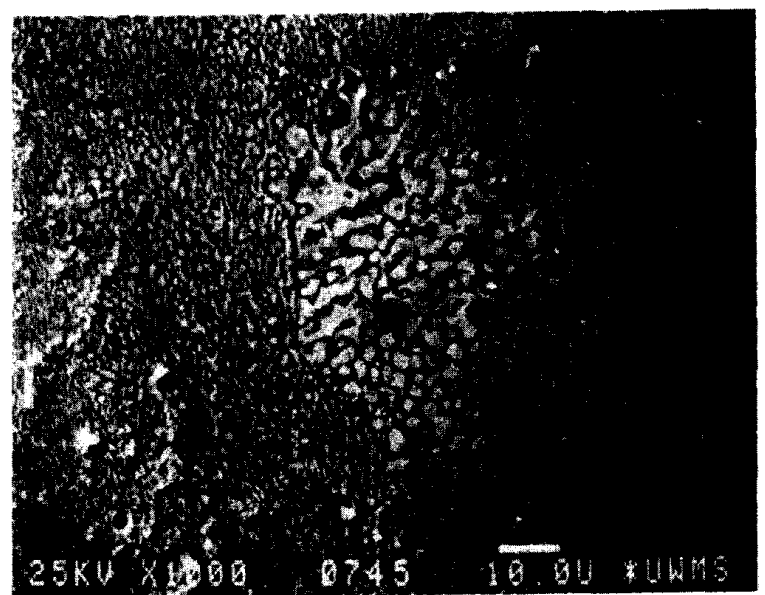

(b)

Figure 2. a) Secondary electron image (SEI) of solder joint prior to thermal cycling; b) Backscattered electron image (BEI) illustrating orientations of various colonies.

Smeby [14]. Also, Smeby [14] and Summers and Morris [16] have reported recrystallization during cyclic loading. Whether the coarseness of the features in figure 4 is due to recrystallization is being investigated.

Figure 5 compares surfaces of various solder fillets after thermal cycling. Note that the surface of each fillet has roughened considerably compared to that prior to cycling, figure 2a. A closer inspection of the surface, figure 6 , reveals the roughening is due to relative sliding between colonies, or "grains," in the eutectic. Because SEI contrasts surface relief most strongly, SEI micrographs such as those in figures 5 and $6 \mathrm{a}$ show the presence of offsets and cracks between 


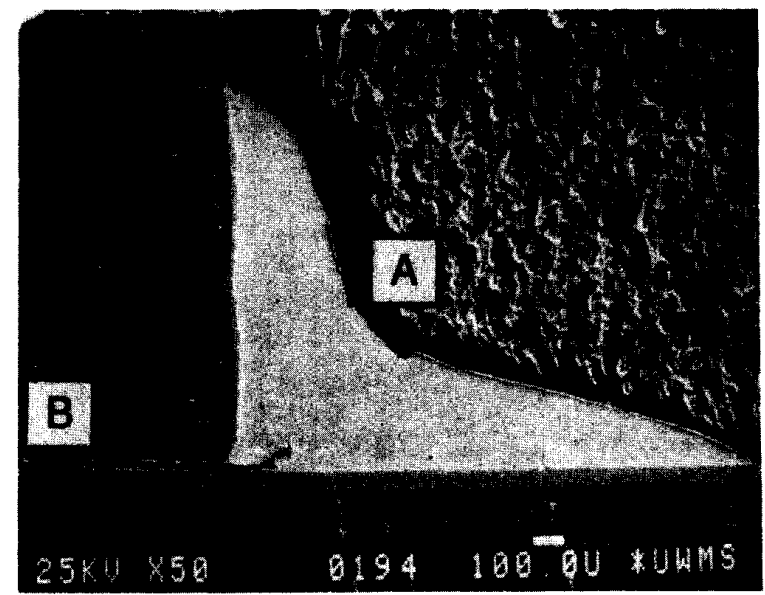

Figure 3. Cross-section of solder joint after 50 cycles between $-35^{\circ} \mathrm{C}$ and $125^{\circ} \mathrm{C}$ (SEI).

grains. A fraction of the grains are pushed out from the surface, while others rotate, etc. Many of the grains, such as the one in the center of $6 \mathrm{a}$, show roughening of the surface, indicative of plastic deformation within the grain. The BEI micrograph, figure $6 \mathrm{~b}$, contrasts $\mathrm{Pb}$ and $\mathrm{Sn}$ phases and unambiguously distinguishes between colonies of lamellae.

Cross-sections of the solder joints after cycling confirm the shear between individual colonies, figure 7 . A-cracks, shown in cross-section, originate at the sliding boundaries, and slowly grow into the specimen.

\section{Discussion}

The presence of the textural features in figures 5 , 6 , and 7 is ample evidence of sliding between colonies. This study shows, therefore, that the sliding between colonies plays a significant role in the rheology of the eutectic solder joint. Because grain boundary sliding is a low strain rate phenomenon [16], and because it is observed at a cycling frequency of $1 / \mathrm{hr}$, its presence can be expected during thermal or mechanical cycling at frequencies lower than $1 / \mathrm{hr}$. Grain boundary sliding will not occur under cycling at high frequencies [9].

The fatigue lives of the solder joints studied here are controlled by growth of the B-crack. Boundaries between individual phases are preferred paths for travel of the B-crack, but whether these boundaries also undergo sliding is unknown. It is therefore premature to state definitively whether, in these solder joints, the process of fatigue is strongly related to grain boundary sliding. If, however, fatigue life is affected by sliding, an obvious next step is to speculate on what the effects might be.

In this respect, there are some simple models that can help. In a model by Baik and Raj [17] wedge cracking is important at intermediate frequencies, and causes intergranular failure and a reduction in fatigue life within this regime. Grain boundary contamination is not a factor; instead, grain boundary sliding causes growth of wedge cracks homogeneously throughout the
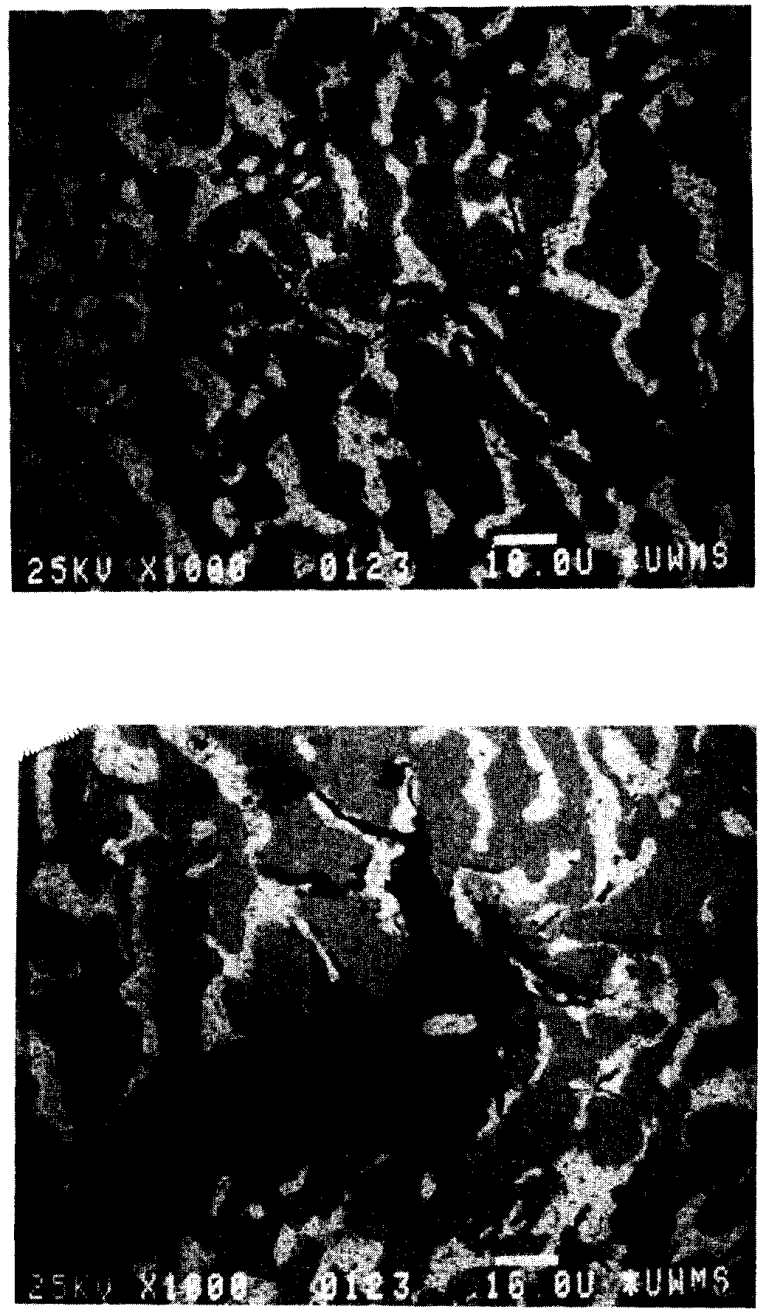

Eigure 4. Cross-sections of solder joints after 50 cycles between $-35^{\circ} \mathrm{C}$ and $125^{\circ} \mathrm{C}$.

bulk of the material. The fatigue life according to the model of Baik and Raj is shown schematically as the dashed line in figure 8 . In Stone's model [9], exposure of grain boundaries to air leads to crack growth. The prediction of Stone's model is shown as a solid line in figure 8.

Both models predict number of cycles to failure will be independent of frequency at high frequencies where grain boundary sliding does not occur. Both predict reduction in fatigue life at intermediate frequencies. However, the model of Baik and Raj predicts fatigue life will improve at very low frequencies, while Stone's model predicts fatigue life will saturate at a minimum value at low frequencies. 


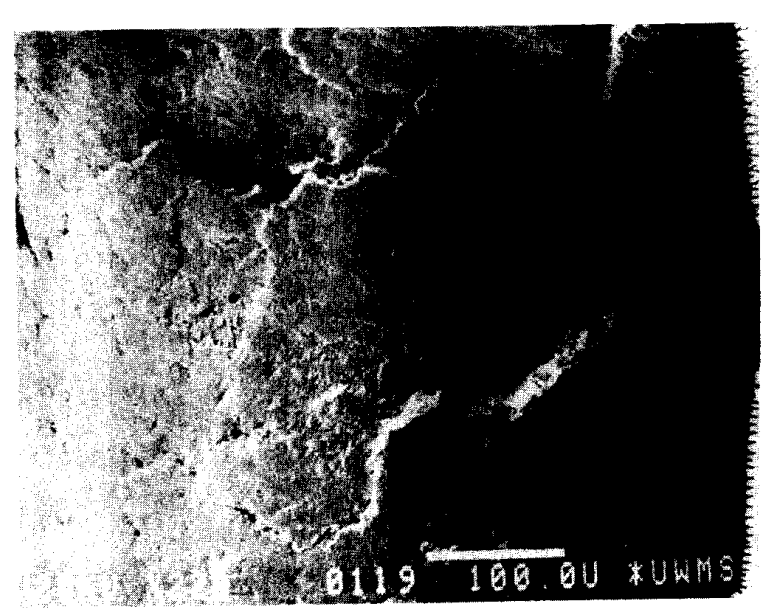

(a)

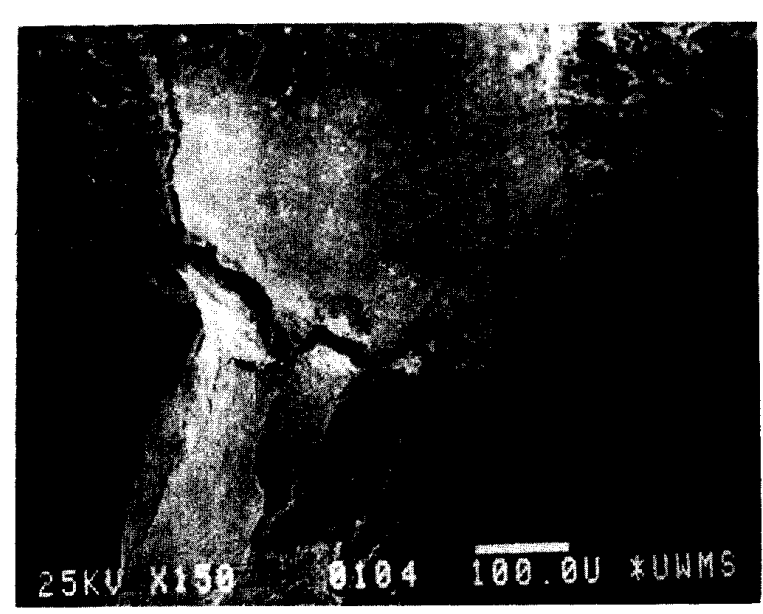

(b)

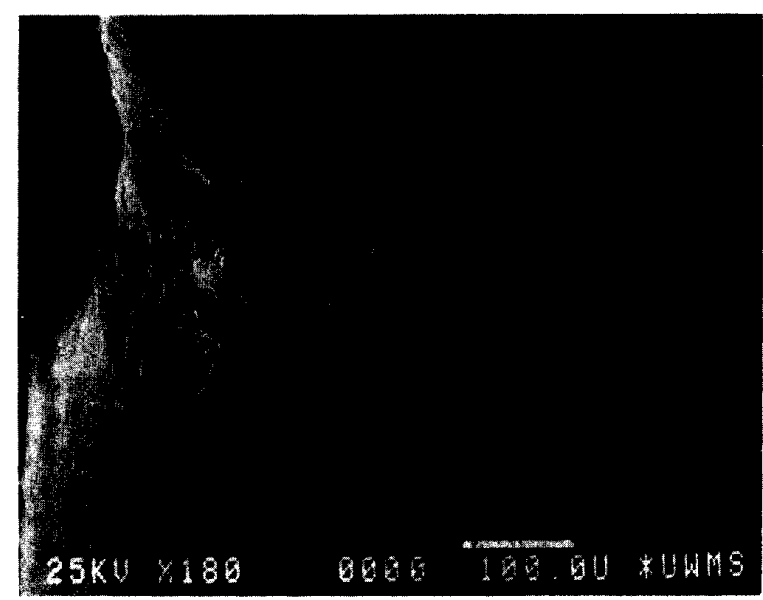

(c)

Figure 5. Surfaces of solder joints after a) 50 cycles between $-35^{\circ} \mathrm{C}$ and $125^{\circ} \mathrm{C}$; b) 200 cycles between $-35^{\circ} \mathrm{C}$ and $125^{\circ} \mathrm{C}$; c) 400 cycles between $-20^{\circ} \mathrm{C}$ and $75^{\circ} \mathrm{C}$. (SEI)

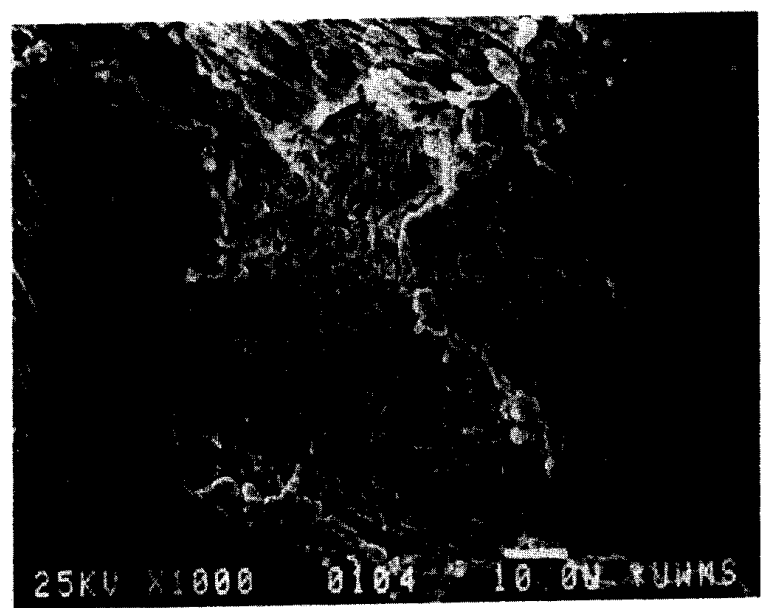

(a)

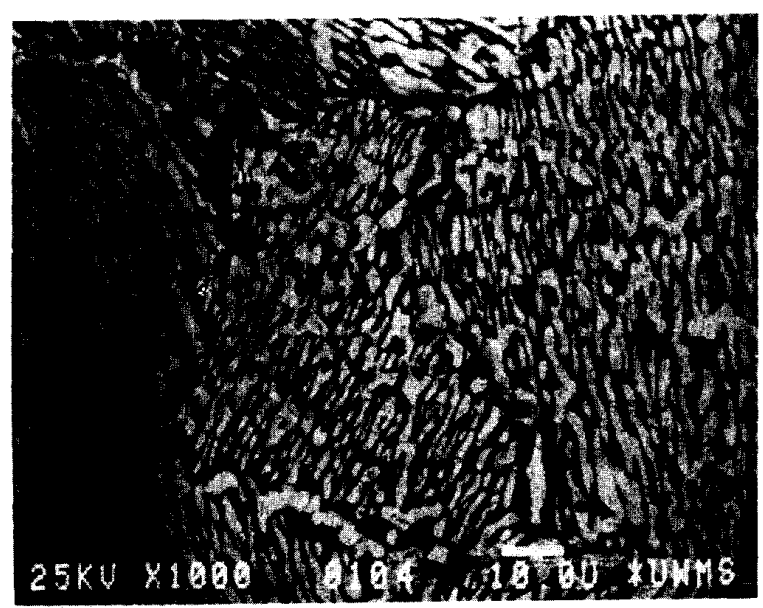

(b)

Figure 6. Close-up of solder joint surface after $200 \mathrm{cy}$ cles between $-35^{\circ} \mathrm{C}$ and $125^{\circ} \mathrm{C}$ : a) $\mathrm{SEI}$ mode of imaging; b) BFI mode.

\section{Acknowledgements}

The authors are indebted to J. Wooldridge of Rockwell International in Cedar Rapids Iowa for donating the specimens tested in this work. The aid of $L$. Casper in setting up the thermal cycling chamber is much appreciated. The electron microscopy was performed on Materials Science Program facilities under supervision of R. Noll. This research was supported by the Wisconsin Alumni Research Foundation. B.D. Stone aided in the preparation of this manuscript. 

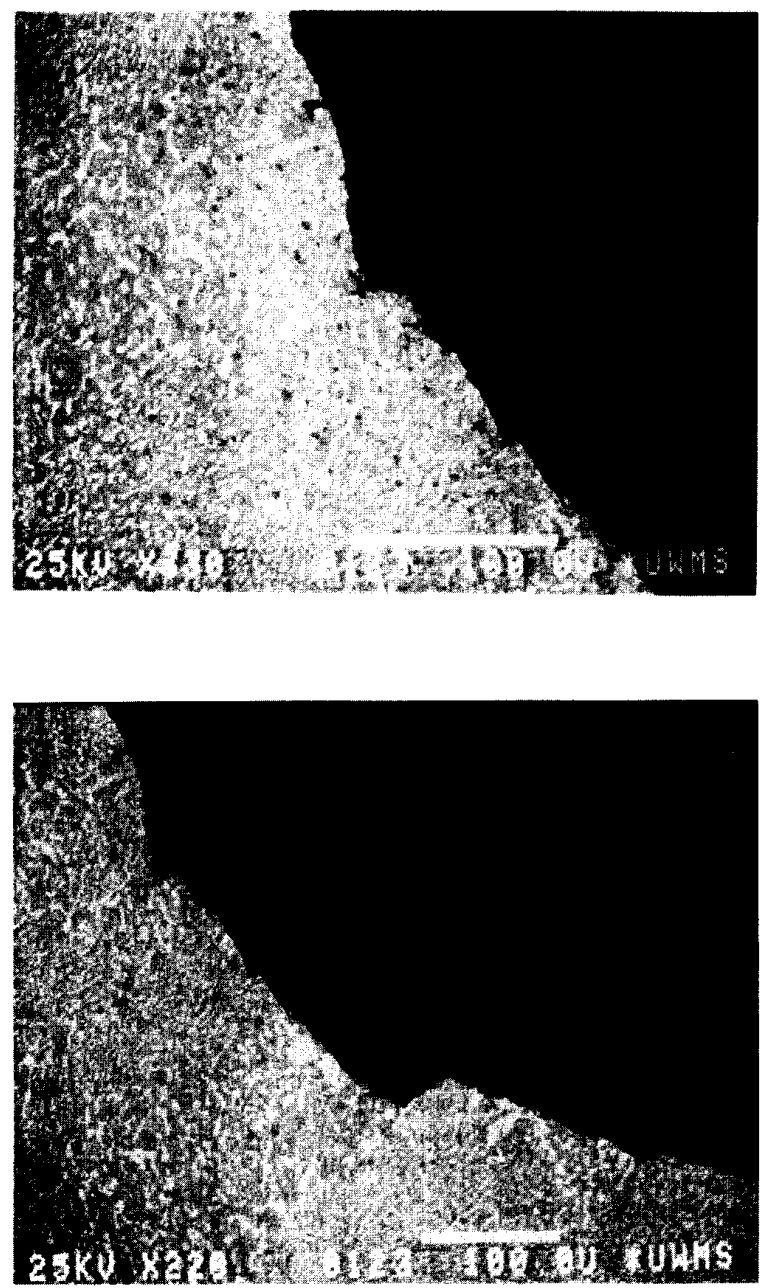

Figure 7. Cross-sections of the solder fillet surfaces demonstrating shear that occurs between colonies and A-cracks initiating at boundaries between colonies. (BEI mode; 50 cycles between $-35^{\circ} \mathrm{C}$ and $125^{\circ} \mathrm{C}$ )

\section{References}

[1] K.U. Snowden. Acta Metall. 12 March (1964) pp. 295-303.

[2] V. Raman and T.C. Reiley. Metall. Trans. A, 19A June (1988) pp. 1533-1546.

[3] S. Vaynman, M.E. Fine, and D.A. Jeannotte. Metall. Trans. A. 19A April (1988) pp. 1051-1059.

[4] E. Levine and J. Ordonez. IEEE CHMT 4(4) December (1981) pp. 515-519.

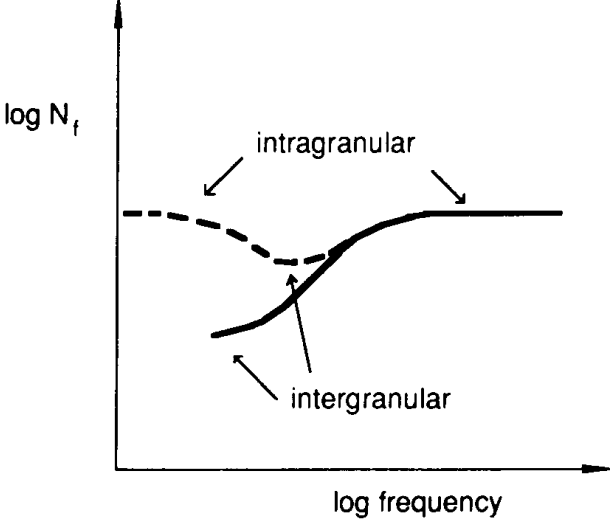

Figure 8 Predictions of dependence of fatigue life on strain range and cycle frequency. The dashed curves are after Baik and Raj [17], while the solid curves are after Stone [9].

[5] H.D. Solomon, in Low Cycle Fatigue, ASTM-STP 942, H.D. Solomon, Ed., ASTM (1988) pp. 342-371.

[6] V. Raman and T.C. Reiley. J. Mat. Sci. Let. 6 May (1987) pp. 549-551.

[7] L.F. Coffin. Proc. Instn. Mech. Engrs. 188 September (1974) pp. 109-127.

[8] S.A. Tetelman and A.J. McEvily, Jr. Fracture of Structural Materials, John Wiley and Sons (1967) p. 375 .

[9] D. Stone, to be published in ASME J. Electr. Pack.

[10] R. Berriche, S. Vaynman, M.E. Fine, and D.A. Jeannotte. Proc. 3rd Conf, Electr. Pack. Mat. Proc. Corr. Microelectr. ASM, IEEE, NACE (1987) pp. 169-174.

[11] D. Stone, S.-P. Hannula, and C.-Y. Li. Proc. 35th ECC. IEEE (1985) pp. 46-51.

[12] T.C. Reiley and D.Y. Shih. in Microelectronics Packaging Handbook, R.R. Tummala and E.J. Rymaszewski, Eds. Van Nostrand-Reinhold, NY (1989) pp. 779-851.

[13] M. Cagnon, M. Suery, A. Eberhardt, and B. Baudelet. Acta Metall. 25 (1977) pp. 71-75.

[14] J.M. Smeby. Proc. 34th ECC IEEE (1984) pp. 117 124.

[15] D. Stone and S.-M. Lee. Proc. SMART VI, Vol. 2, IPC, EIA, (1990) pp. 57-65.

[16] T.S.E. Summers and J.W. Morris, Jr. to be published in ASME J. Electr. Pack.

[17] S. Baik and R. Raj. Metall. Trans. A, 13A July (1972) pp. 1207-1214. 